Article

\title{
The Hypothermic Influence on CHOP and Ero1- $\alpha$ in an Endoplasmic Reticulum Stress Model of Cerebral Ischemia
}

\author{
Gagandip K. Poone, Henrik Hasseldam, Nina Munkholm, Rune S. Rasmussen, \\ Nina V. Gronberg and Flemming F. Johansen *
}

Department of Biomedical Sciences and Biotech Research \& Innovation Centre (BRIC), University of Copenhagen, 2200, Denmark; E-Mails: gagandipkb@hotmail.com (G.K.P.);

henrik.hasseldam@bric.ku.dk (H.H.);nmunkholm@hotmail.com (N.M.); rsr@sund.ku.dk (R.S.R.); ninavg@sund.ku.dk (N.V.G.)

* Author to whom correspondence should be addressed; E-Mail: ffj@sund.ku.dk;

Tel.: +45-287-56-040; Fax: +45-353-25-669.

Academic Editor: Bruno Meloni

Received: 6 February 2015 / Accepted: 7 May 2015 / Published: 15 May 2015

\begin{abstract}
Hypoxia induced endoplasmic reticulum stress causes accumulation of unfolded proteins in the endoplasmic reticulum and activates the unfolded protein response, resulting in apoptosis through CCAAT-enhancer-binding protein homologous protein (CHOP) activation. In an in vitro and in vivo model of ischemic stroke, we investigated whether hypothermia regulates the unfolded protein response of $\mathrm{CHOP}$ and Endoplasmic reticulum oxidoreductin- $\alpha$ (Ero1- $\alpha$ ), because Ero1- $\alpha$ is suggested to be a downstream CHOP target. The gene expression of CHOP and Ero1- $\alpha$ was measured using Quantitative-PCR (Q-PCR) in rat hippocampi following global cerebral ischemia, and in hypoxic pheochromocytoma cells during normothermic $\left(37{ }^{\circ} \mathrm{C}\right)$ and hypothermic $\left(31^{\circ} \mathrm{C}\right)$ conditions. As a result of ischemia, a significant increase in expression of CHOP and Ero1- $\alpha$ was observed after three, six and twelve hours of reperfusion following global ischemia. A stable increase in CHOP expression was observed throughout the time course $(p<0.01, p<0.0001)$, whereas Ero1- $\alpha$ expression peaked at three to six hours $(p<0.0001)$. Induced hypothermia in hypoxia stressed PC12 cells resulted in a decreased expression of CHOP after three, six and twelve hours $(p<0.0001)$. On the contrary, the gene expression of Ero1- $\alpha$ increased as a result of hypothermia and peaked at twelve hours $(p<0.0001)$. Hypothermia attenuated the expression of CHOP, supporting that hypothermia suppress endoplasmic reticulum stress induced apoptosis in stroke. As hypothermia further induced up-regulation of Ero1- $\alpha$, and since CHOP and Ero1- $\alpha$ showed
\end{abstract}


differential regulation as a consequence of both disease (hypoxia) and treatment (hypothermia), we conclude that they are regulated independently.

Keywords: brain ischemia; unfolded protein response; transcription factor CHOP; Ero1- $\alpha$ protein; hypoxia-inducible factor-proline dioxygenases; stroke

\section{Introduction}

Hypothermia is a promising treatment strategy following several medical conditions such as traumatic brain injury, myocardial infarction, cardiac arrest, and ischemic stroke [1-4]. Contrary to single target therapies, hypothermia aims at multiple targets, exerting protection by altering a variety of detrimental effects. The benefits of therapeutic cooling have been demonstrated in several experimental in vitro and in vivo studies of cerebral ischemia [5-9]. Overall, these investigations found improvements in metabolism, inhibition of inflammatory mediators, regulation of gene expression, improved blood brain barrier (BBB) integrity, and regulation of the balance between cell death and survival following an ischemic stroke.

Cerebral ischemia causes hypoxic stress in cells, leading to endoplasmic reticulum (ER), environment disruption, and accumulation of unfolded proteins in the ER lumen. In response to cellular aggregation of misfolded and/or unfolded proteins, the Unfolded Protein Response (UPR) becomes activated [10,11]. The UPR will initially induce translational attenuation, transcriptional up-regulation of ER chaperones and enhance unfolded protein degradation in an attempt to prevent further cellular damage, overcome the insult, and restore normal ER function. If stress is severe or prolonged, the UPR triggers cell death [11,12].

In unstressed cells, the ER chaperone glucose-regulated-protein (GRP78) binds pancreatic-ER-kinase (PERK), inositol-requiring ER-transmembrane RNAse-1 (IRE-1) and activating-transcription factor-6 (ATF6), keeping them inactivated [13]. Upon stress, ER calcium depletion and, thereby, an enhanced load of unfolded proteins, GRP78 is titrated away from PERK, ATF6, and IRE-1 by binding the unfolded proteins instead, leading to activation of the UPR actors. Downstream from these pathways is the activation of the CCAAT-enhancer-binding protein homologous protein (CHOP), a pro-apoptotic transcription factor [13-15].

CHOP plays a central role in the ischemic damage resulting in neuronal death [10]. Many CHOP targets have been identified, amongst these growth arrest and DNA damage-inducible protein (GADD34) and Bcl-2, all serving to mediate apoptosis [16].

Endoplasmic reticulum oxidoreductin- $\alpha$ (Ero1- $\alpha$ ) has also been suggested to be a CHOP target gene [15]. Ero1 exists in two forms, Ero1- $\alpha$ and Ero1- $\beta$. Ero1- $\alpha$ is an oxidoreductase that relays disulfide bonds to protein disulfide isomerase (PDI), which helps ER proteins to obtain correct conformation [15]. Some investigations also suggest that Ero1- $\alpha$ is responsible for inositol 1,4,5-triphosphate (IP3) receptor induced $\mathrm{Ca}^{2+}$ release, initiating apoptosis [16]. Thus, the association between CHOP and Ero1- $\alpha$ in ischemic brain damage and a possible therapeutic influence of hypothermia remains unclear. 
In an experimental animal model of global ischemia, we investigated relative changes in the expression of CHOP and Ero1- $\alpha$ following ischemia. Subsequently, in an in vitro model, we mimicked the ischemic condition by introducing hypoxia into a neuron-like cell line and applied hypothermic conditions to evaluate the effects of hypothermia on the transcriptional levels of these mediators.

\section{Methods}

\subsection{Animals and Cell Lines}

Sixty male Wistar rats (aged 9 weeks, weighing 280-300 g) obtained from Taconic (Ry, Denmark) were cared for according to the guidelines and approvals of the Department of Experimental Medicine, University of Copenhagen, Denmark, and all the experiments were conducted according to the Danish Animal Experiments Committee (\#2012-DY-2934). Animals were acclimatized for 7 days prior to surgery and allowed free access to food and water under diurnal lighting conditions. All efforts were made to diminish pain, suffering and stress of the animals.

PC12 cells are a commercially available rat pheocromocytoma cell line originating from rat adrenal medulla (ATCC, Boras, Sweden). PC12 cells were grown on collagen (Sigma-Aldrich, Copenhagen, Denmark) coated (6 ug/mL) dishes with DMEM (Life Technologies, Naerum, Denmark), supplemented with horse serum (Life technologies), fetal bovine serum (Life technologies) and penicillin/streptomycin (Life technologies) (10/5/1\%) and cultured in a standard incubation chamber $\left(5 \% \mathrm{CO}_{2} / 21 \% \mathrm{O}_{2}\right)$. Cells were plated at a density of $1-2 \times 10^{4}$ cells $/ \mathrm{cm}^{2}$.

\subsection{Global Cerebral Ischemia}

Rats were subjected to experimental global ischemia by the two-vessel occlusion (2-VO) model during systemic hypotension [17]. Anesthesia was induced (4\%) and maintained (1\%-2\%) with isoflurane in $30 \% / 70 \% \mathrm{NO} / \mathrm{O}_{2}$, and a femoral catheter was embedded to keep animals hypotensive, which also allowed for arterial blood-sampling throughout surgery. Blood gases were analyzed on a Radiometer ABL 555 blood gas analyzer (Radiometer, Brønshøj, Denmark). As global brain ischemia may impede respiratory system functions, ventilator-controlled respiration was performed with a Harvard 683 small animal ventilator (Scandidact, Odder, Denmark). Both common carotid arteries were gently exposed and systemic hypotension $(50 \mathrm{mmHg})$ was induced with a heparinized syringe through the femoral catheter. Arteries were then fully ligated for $12 \mathrm{~min}$. with subsequent removal of ligatures and reperfusion of 3, 6 and $12 \mathrm{~h}$ ( $n=10$ /group). Incision wounds were treated with lidocain gel (10 mg/mL; Region Hovedstadens Apotek, Copenhagen, Denmark). At the end of reperfusion, rats were deeply anesthetized, decapitated, and brains were rapidly removed, snap frozen in isopentane and stored at $-80{ }^{\circ} \mathrm{C}$. Dorsal and ventral parts of the hippocampus were carefully dissected on ice and added TRIzol reagent (Invitrogen) to avoid RNA degradation prior to RNA isolation.

\subsection{Thapsigargin and Hypoxia Stressed PC12 Cells}

Confluent PC12 cells were incubated with $0.32 \times 10^{-5} \mathrm{M}$ thapsigargin (Sigma-Aldrich) for $1 \mathrm{~h}, 4 \mathrm{~h}$ or $24 \mathrm{~h}$ at either $37^{\circ} \mathrm{C}$ or $31^{\circ} \mathrm{C}$ in a standard incubator, in order to establish a positive control for UPR activation in the cell line. To identify suitable working concentrations, a survival MTT (Methylthiazol 
Tetrazolium Bromid, Sigma-Aldrich) assay was performed with 10 different thapsigargin concentrations $\left(0.02 \times 10^{-5} \mathrm{M}\right.$ to $\left.10.24 \times 10^{-5} \mathrm{M}\right)$. A control sample of untreated PC12 cells with the lowest corresponding DMSO concentration $(0.031 \%)$ was incubated for $24 \mathrm{~h}$ at $37{ }^{\circ} \mathrm{C}$. One biological sample for each treatment parameter was generated.

Three biological samples of $\mathrm{PC} 12$ cells (grown to confluency at $37^{\circ} \mathrm{C}$ ) were incubated at $37{ }^{\circ} \mathrm{C}$ or $31{ }^{\circ} \mathrm{C}$ for $1 \mathrm{~h}, 3 \mathrm{~h}, 6 \mathrm{~h}$ or $12 \mathrm{~h}$ in a hypoxic incubation chamber with $0.3 \% \mathrm{O}_{2}$, controlled with nitrogen.

Three biological control samples were incubated for $12 \mathrm{~h}$ in a standard incubator $\left(5 \% \mathrm{CO}_{2}\right)$ at $37{ }^{\circ} \mathrm{C}$. Biological triplicates were generated for each treatment parameter (time/temperature). At the end of incubation time, cells quickly proceeded to RNA isolation.

\subsection{RNA Extraction and Complementary DNA (cDNA) Synthesis}

RNA extraction was performed according to the TRIzol reagent protocol (Life Technologies) and measured on a BioPhotometer 6131 spectrophotometer (Eppendorf, Hamburg, Germany).

RNA samples were reverse transcribed using the ImProm-II Reverse Transcription System (Qiagen, Copenhagen, Denmark). Thermal cycling conditions were set to $5 \mathrm{~min}$ at $25{ }^{\circ} \mathrm{C}$ for annealing, $60 \mathrm{~min}$ at $42{ }^{\circ} \mathrm{C}$ for extension and $15 \mathrm{~min}$ at $70{ }^{\circ} \mathrm{C}$ for inactivating the reverse transcriptase enzyme. From this reaction, a cDNA concentration of $0.05 \mu \mathrm{g} / \mu \mathrm{L}$ was obtained.

\subsection{Quantitative-PCR}

All samples were prepared in triplicates for the targets CHOP, Ero1- $\alpha$, and Hmbs (normalization target). Primers for the housekeeping gene Hmbs, HPRT, synaptophysin, and $\beta$-actin were tested for stability during hypoxia under normo- and hypothermic conditions. Hmbs exhibited highly stable expression, which is why this gene was chosen as the normalization target for further studies.

The Q-PCR reactions were performed using the ABI 7300 Detection System (Life Technologies). In a $25 \mu \mathrm{L}$ reaction, $2 \mu \mathrm{L}$ cDNA $(100 \mathrm{ng} / 2 \mu \mathrm{L}), 3 \mu \mathrm{L}$ nuclease free $\mathrm{H}_{2} \mathrm{O}, 7.5 \mu \mathrm{L}$ relevant primers (forward + reverse, $2000 \mathrm{nM}$ ), and $12.5 \mu \mathrm{L}$ RealQ-PCR dUTP Master Mixes Kit (Ampliqon, Odense, Denmark) was used for a total of $25 \mu \mathrm{L}$. Thermal cycling conditions were: fifteen minutes at $95{ }^{\circ} \mathrm{C}$ (for hot start of the Taq DNA polymerase enzyme), forty cycles at $95{ }^{\circ} \mathrm{C}$ for $30 \mathrm{~s}$ (dissociation of cDNA strings), $60^{\circ} \mathrm{C}$ for $1 \mathrm{~min}$ (annealing of primers), and $72^{\circ} \mathrm{C}$ for $30 \mathrm{~s}$ (extension).

Dissociation curves were included in all runs-one cycle of $95^{\circ} \mathrm{C}$ for $30 \mathrm{~s}, 50{ }^{\circ} \mathrm{C}$ for $30 \mathrm{~s}$, and from $50{ }^{\circ} \mathrm{C}$ to $95^{\circ} \mathrm{C}$, with a reading every $0.5^{\circ} \mathrm{C}$ and a hold for $10 \mathrm{~s}$.

Primers used: Hmbs (76 base pairs (bp), F: TCTAGATGGCTCAGATAGCATGCA, R: TGGACCATCTTCTTGCTGAACA), CHOP (100 bp, F: CCT GAA AGC AGA AAC CGG TC, R: CCT CAT ACC AGG CTT CCA GC) and Ero1- $\alpha$ (204 bp, F: TTA AGT CTG CGA GCT ACA AGT ATT C, R: AGT AAA TCC ACA TAC TCA GCA).

\subsection{Statistical Analysis}

All data are calculated according to the comparative $\mathrm{Ct}$ method and expressed as mean $\pm \mathrm{SD}$, presenting data as fold change in gene expression normalized to housekeeping gene (Hmbs) and relative to the untreated control, an approach determining the relative quantification rather than 
absolute quantification [18]. Ordinary one-way analysis of variance (ANOVA) was used for comparisons between different groups followed by Tukey's multiple comparisons test. Data indicated that temperature has an influence on the mean fold changes of both CHOP and Ero1- $\alpha$ during the $12 \mathrm{~h}$ of reperfusion. Thus, a two-way ANOVA was performed to test if there was an interaction between temperature and time followed by multiple pairwise comparisons by the Holm-Sidak method. $p<0.05$ was considered statistically significant.

\section{Results}

\subsection{Global Cerebral Ischemia Induces Up-regulation of CHOP and Erol- $\alpha$ in Rat Hippocampi}

Induction of global ischemia altered the expression level of CHOP and Ero1- $\alpha$ in hippocampi of Wistar rats (Figure 1). A stable CHOP increase was observed throughout the entire time course. At 3 and $12 \mathrm{~h}$ of reperfusion, CHOP was found to be significantly up-regulated compared to untreated, control animals $(p<0.01)$. At $6 \mathrm{~h}$ of reperfusion, CHOP levels were further increased $(p<0.0001)$, however not significantly different from the 3 and $12 \mathrm{~h}$ group. Similar to CHOP, Ero1- $\alpha$ was also increased at 3 to $6 \mathrm{~h}$ following ischemia $(p<0.0001)$, although it seemed to reach maximum at this time point and was reduced towards normal levels after $12 \mathrm{~h}$ of reperfusion. Nevertheless, 3, 6 and $12 \mathrm{~h}$ after ischemic injury all show significant up-regulation of Ero1- $\alpha$ compared to untreated controls $(p<0.0001$ and 0.01 respectively).

\section{Hippocampal expression at 3,6 and $12 \mathrm{~h}$ of reperfusion}

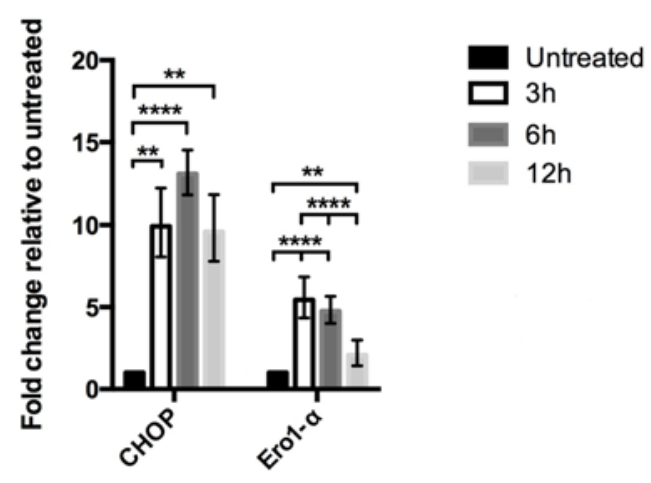

Figure 1. Hippocampal expression of CHOP and Ero1- $\alpha$ following global ischemia. Quantitative PCR revealed a significant increase in expression of CHOP and Ero1- $\alpha$ induced by global ischemia over a time course of $12 \mathrm{~h}$. The greatest expression level of $\mathrm{CHOP}$ is detected at $6 \mathrm{~h}$ of reperfusion $(n=6)$ compared to untreated animals $(n=10)$, $(p<0.0001)$. At $3 \mathrm{~h}(n=7)$ and $12 \mathrm{~h}(n=6)$ after induction of ischemia similar expression levels of CHOP were observed, significantly greater than in the untreated group $(p<0.01)$. No difference between the different time points was detected. Ero1- $\alpha$ was significantly increased at $3 \mathrm{~h}(n=5), 6 \mathrm{~h}(n=7)$ and $12 \mathrm{~h}(n=5)$ of reperfusion ( $p<0.0001$ and 0.01 respectively), with greatest expression levels at 3 to $6 \mathrm{~h}$ followed by a decrease. Data analyzed by one-way ANOVA followed by Tukey's multiple comparisons test. $* * p<0.01$ and $* * * * p<0.0001$. 


\subsection{Thapsigargin and Verification of PC12 Cell Suitability}

Thapsigargin were used in order to verify the suitability of PC12 cells in our experimental setup. Both CHOP (Figure 2a) and ERO1- $\alpha$ (Figure 2b) mRNA were significantly changed following hypothermia, although in opposite directions. Quantification of four different housekeeping genes showed that Hmbs were stably expressed under all experimental conditions (Figure 2c,d).

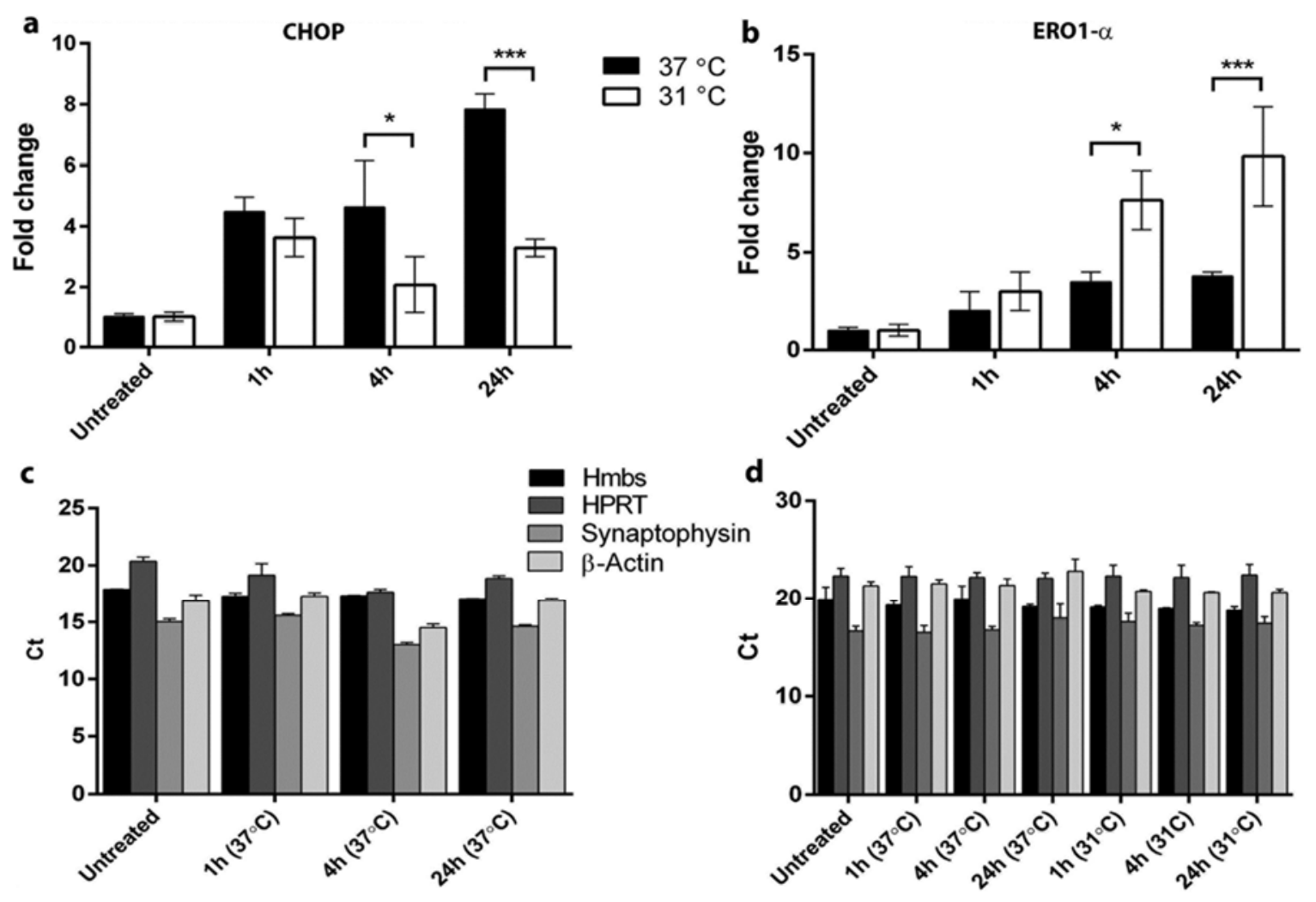

Figure 2. Control experiments performed in order to verify the usefulness of our in vitro model and to test the stability of several housekeeping genes in vitro and in vivo. PC12 cells were incubated under hypoxic conditions for $1 \mathrm{~h}, 4 \mathrm{~h}$, and $24 \mathrm{~h}$ at either $37{ }^{\circ} \mathrm{C}$ or $31^{\circ} \mathrm{C}$. Expression levels of CHOP mRNA decreased as a consequence of hypothermia at $4 \mathrm{~h}(p<0.05)$ and $24 \mathrm{~h}(p<0.001)(\mathbf{a})$; whereas ERO1- $\alpha$ mRNA increased following $4 \mathrm{~h}$ $(p<0.05)$ and $24 \mathrm{~h}(p<0.001)(\mathbf{b})$; Threshold cycle values $(\mathrm{Ct})$ of four different housekeeping genes in hippocampus (c) and PC12 cells (d), revealed that Hmbs was stably expressed under hypoxia at both $31^{\circ} \mathrm{C}$ and $37^{\circ} \mathrm{C}$.

\subsection{Hypothermia Attenuates CHOP and Augments Erol- $\alpha$ Expression in Hypoxic Cells in Vitro}

With the use of a SERCA (sarco/endoplasmatic reticulum $\mathrm{Ca}^{2+}$-ATPase) pump inhibitor, thapsigargin, a suitable concentration for induction of a UPR response in the PC12 cell line was found (data not shown), confirming the ability of the cell line to activate UPR upon stress. Since we saw a substantial increase in both CHOP and Ero1- $\alpha$ expression levels at $3 \mathrm{~h}$ in our in vivo model, we included an additional $1 \mathrm{~h}$ group subjected to hypothermic conditions. Messenger RNA expression of the two UPR markers was unaffected after $1 \mathrm{~h}$ of hypoxia, whereas 3, 6, and $12 \mathrm{~h}$ of hypoxia showed similar expression patterns as seen in vivo (Figure 3). However, results indicate that PC12 cells 
respond slightly different to hypoxia compared to hippocampal neurons, where $12 \mathrm{~h}$ of hypoxia further increases the expression levels of CHOP, in contrast to the decreased levels observed in our in vivo model (Figure 1). Ero1- $\alpha$ expression patterns in PC12 cells also resemble what we found in vivo; however, $6 \mathrm{~h}$ of hypoxia seemed to entail the greatest increase in expression. Upon incubation at hypothermic conditions, we found a significant decrease in CHOP expression at 3, 6 and $12 \mathrm{~h}$ compared to normothermic conditions $(p<0.0001)$. In contrast, expression levels of Ero1- $\alpha$ were increased as a result of hypothermia at $6 \mathrm{~h}(p<0.001)$ and $12 \mathrm{~h}(p<0.0001)$ (Figure 3).
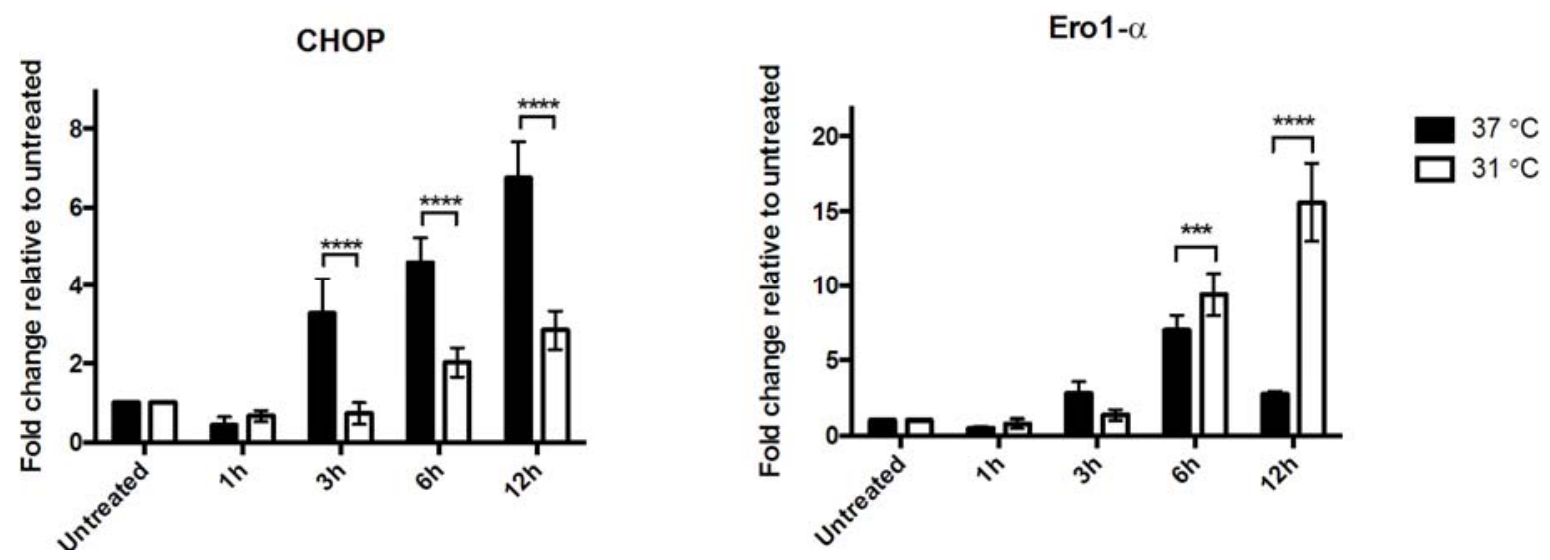

Figure 3. Expression of CHOP and Ero1- $\alpha$ in hypoxic PC12 cells under normo- and hypothermic conditions. Quantitative PCR revealed increased expression levels of CHOP and Erol- $\alpha$ over a $12 \mathrm{~h}$ time course under normothermic conditions. This is consistent with findings in the global ischemia in vivo model. Hypothermia attenuated the expression of CHOP significantly $(p<0.0001)$ at $3(n=6), 6(n=5)$ and $12 \mathrm{~h}(n=5)$. The expression levels of Ero1- $\alpha$ were augmented by hypothermic conditions with marginally increased levels at $6 \mathrm{~h}(n=6)$ and significantly increased levels at $12 \mathrm{~h}(n=5)$. *** $p<0.001$ and $* * * * p<0.0001$.

\section{Discussion}

In our study, global cerebral ischemia was associated with increased transcriptional levels of CHOP and Ero1- $\alpha$. Whereas high CHOP expression was maintained throughout the study period, ERo1- $\alpha$ peaked at 3 to $6 \mathrm{~h}$ (ischemia) and $6 \mathrm{~h}$ (hypoxia), respectively. Additionally, we found that hypothermia $\left(31{ }^{\circ} \mathrm{C}\right)$ during hypoxia modulated the ER stress response through downregulation of CHOP after 3,6 and $12 \mathrm{~h}$ and up-regulation of Erol- $\alpha$ after 6 and $12 \mathrm{~h}$. The fact that these two genes are differentially expressed, both as a consequence of disease induction (hypoxia) and treatment (hypothermia), suggests that they are independently regulated.

Current research suggests that hypothermia causes alterations in the expression of ER stress related genes. Amongst these, an increased expression of the protective GRP78 has been identified, and decreased expression of proapoptotic factor CHOP and, thereby, a reduction in apoptosis [19-20]. Furthermore, hypothermia is known to induce neuroprotection both in vivo [19-20] and in vitro [21]. Ero1- $\alpha$ has been identified as a CHOP target; however, contradictory evidence on signaling molecules leading to activation of the two isoforms Ero1- $\alpha / \beta$ exists $[15,22,23]$. 
An increase in CHOP expression up to $24 \mathrm{~h}$ following global ischemia, associated with death of hippocampal neurons, has previously been shown [19]. Furthermore, $3 \mathrm{~h}$ of hypothermia decreased CHOP expression in vivo [19] in agreement with our in vitro results.

In contrast, an augmentation of Ero1- $\alpha$ in hypoxic cells at hypothermic conditions was observed. To our knowledge, investigations of the role of Ero1- $\alpha$ in apoptotic pathways following ischemia as well as the influence of hypothermia are lacking. Erol- $\alpha$ is assumed to be regulated through hypoxia-inducible-factor-1 (HIF-1), a cytosolic transcription factor which is increased in response to low oxygen tension, while Ero1- $\beta$ is assumed to be regulated through the UPR [22,23]. Furthermore, it has been suggested that Ero1- $\alpha$ is a CHOP target, whilst Ero1- $\beta$ induction is unaffected by CHOP expression [15]. Since Ero1- $\alpha$ expression in our study is augmented in hypothermic conditions and CHOP is attenuated, a regulation independent of CHOP is indicated. Hence, Ero1- $\alpha$ up-regulation is likely to be attained through the HIF-1 pathway in response to low oxygen tension. Plausibly, hypothermia amplifies the HIF-1 induction, leading to increased expression of Ero1- $\alpha$ in cells stressed with hypoxia.

It should be noted that the PC12 cell line is derived from electrically inexcitable pheochromocytes. Therefore, the results seen in our PC12 cells, in particular the lack of downstream CHOP effects on Ero1- $\alpha$, should be further confirmed in neurons in vivo. Another shortcoming of the study is that our results only address the transcriptional levels. In a broader translational perspective, experiments with the use of transgenic mice relating ischemic damage to specific UPR proteins may highlight whether regulating proteins of the UPR truly is neuroprotective.

In agreement with other studies, we show that an ischemic insult results in significant changes in the transcriptional levels of ER stress regulators [11,24]. Our results draw attention to the potential effect of hypothermia on the UPR. In an in vivo and in vitro model of ischemic stroke, we provide evidence that CHOP and Erol- $\alpha$ of the UPR are possible therapeutic targets in ischemic injury. Hypothermia seems to result in a down-regulation of the pro-apoptotic factor CHOP and an increase in Ero1- $\alpha$ expression, thus indicating that hypothermia decouples CHOP-induced transcription of Ero1- $\alpha$. Our results draw attention to the potential effect of hypothermia on the UPR and future studies of CHOP and Ero1- $\alpha$ regulation at the protein level will further substantiate their feasibility as drug targets in stroke treatment.

\section{Acknowledgments}

We thank Lotte Kellemann Kristensen for her contributions to the manuscript and for supporting this investigation.

\section{Author Contributions}

Gagandip K. Poone analysed the data and wrote the paper, Nina Munkholm and Flemming F. Johansen conceived and designed the experiments, Nina Munkholm performed the experiments, and Nina V. Grønberg, Henrik Hasseldam and Rune S. Rasmussen helped analyse data and write the paper. 


\section{Conflicts of Interest}

The authors declare no conflict of interest.

\section{References}

1. Jiang, J.Y.; Xu, W.; Li, W.P.; Gao, G.Y.; Bao, Y.H.; Liang, Y.M.; Luo, Q.Z. Effect of long-term mild hypothermia or short-term mild hypothermia on outcome of patients with severe traumatic brain injury. J. Cereb. Blood Flow Metab. 2006, 26, 771-776, doi:10.1038/sj.jcbfm.9600253.

2. Mottillo, S.; Sharma, K.; Eisenberg, M.J. Therapeutic hypothermia in acute myocardial infarction: A systematic review. Can. J. Cardiol. 2011, 27, 555-561, doi:10.1016/j.cjca.2010.12.027.

3. England, T.N. Mild therapeutic hypothermia to improve the neurologic outcome after cardiac arrest. N. Engl. J. Med. 2002, 346, 549-556, doi:10.1056/NEJMoa012689.

4. Hong, J.M.; Lee, J.S.; Song, H.J.; Jeong, H.; Choi, H.A.; Lee, K. Therapeutic hypothermia after recanalization in patients with acute ischemic stroke. Stroke 2014, 45, 134-140, doi:10.1161/STROKEAHA.113.003143.

5. Krieger, D.W.; Yenari, M.A. Therapeutic hypothermia for acute ischemic stroke: What do laboratory studies teach us? Stroke 2004, 35, 1482-1489, doi:10.1161/01.STR.0000126118.44249.5c.

6. Ohta, H.; Terao, Y.; Shintani, Y.; Kiyota, Y. Therapeutic time window of post-ischemic mild hypothermia and the gene expression associated with the neuroprotection in rat focal cerebral ischemia. Neurosci. Res. 2007, 57, 424-433, doi:10.1016/j.neures.2006.12.002.

7. Wang, J.; Chambers, G.; Cottrell, J.E.; Kass, I.S. Differential Fall in ATP Accounts for Effects of Temperature on Hypoxic Damage in Rat Hippocampal Slices. J. Neurophysiol. 2000, 83, 3462-3472.

8. Zhao, H.; Steinberg, G.K.; Sapolsky, R.M. General versus specific actions of mild-moderate hypothermia in attenuating cerebral ischemic damage. J. Cereb. Blood Flow Metab. 2007, 27, 1879-1894, doi:10.1038/sj.jcbfm.9600540.

9. Liu, L.; Kim, J.Y.; Koike, M.A.; Yoon, Y.J.; Tang, X.N.; Ma, H.; Lee, H.; Steinberg, G.K.; Lee, J.E.; Yenari, M.A. FasL shedding is reduced by hypothermia in experimental stroke. J. Neurochem. 2008, 106, 541-550.

10. Tajiri, S.; Oyadomari, S.; Yano, S.; Morioka, M.; Gotoh, T.; Hamada, J.I.; Ushio, Y.; Mori, M. Ischemia-induced neuronal cell death is mediated by the endoplasmic reticulum stress pathway involving CHOP. Cell Death Differ. 2004, 11, 403-415, doi:10.1038/sj.cdd.4401365.

11. Szegezdi, E.; Logue, S.E.; Gorman, A.M.; Samali, A. Mediators of endoplasmic reticulum stress-induced apoptosis. EMBO Rep. 2006, 7, 880-885.

12. Harding, H.P.; Zhang, Y.; Zeng, H.; Novoa, I.; Lu, P.D.; Calfon, M.; Sadri, N.; Yun, C.; Popko, B.; Paules, R.; et al. An integrated stress response regulates amino acid metabolism and resistance to oxidative stress. Mol. Cell 2003, 11, 619-633.

13. Ni, M.; Lee, A.S. ER chaperones in mammalian development and human diseases. FEBS Lett. 2007, 581, 3641-3651.

14. Hu, B.R.; Martone, M.E.; Jones, Y.Z.; Liu, C.L. Protein aggregation after transient cerebral ischemia. J. Neurosci. 2000, 20, 3191-3199. 
15. Marciniak, S.J.; Yun, C.Y.; Oyadomari, S.; Novoa, I.; Zhang, Y.; Jungreis, R.; Nagata, K.; Harding, H.P.; Ron, D. CHOP induces death by promoting protein synthesis and oxidation in the stressed endoplasmic reticulum. Genes Dev. 2004, 18, 3066-3077.

16. Li, G.; Mongillo, M.; Chin, K.T.; Harding, H.; Ron, D.; Marks, A.R.; Tabas, I. Role of ERO1-alpha-mediated stimulation of inositol 1,4,5-triphosphate receptor activity in endoplasmic reticulum stress-induced apoptosis. J. Cell Biol. 2009, 186, 783-792, doi:10.1083/jcb.200904060.

17. Kalliokoski, O.; Abelson, K.S.; Koch, J.; Boschian, A.; Thormose, S.F.; Fauerby, N.; Rasmussen, R.S.; Johansen, F.F.; Hau, J. The effect of voluntarily ingested buprenorphine on rats subjected to surgically induced global cerebral ischaemia. In Vivo 2010, 24, 641-646.

18. Livak, K.J.; Schmittgen, T.D. Analysis of relative gene expression data using real-time quantitative PCR and the 2(-Delta Delta C(T)) Method. Methods 2001, 25, 402-408, doi:10.1006/meth.2001.1262.

19. Liu, X.; Wang, M.; Chen, H.; Guo, Y.; Ma, F.; Shi, F.; Bi, Y.; Li, Y. Hypothermia protects the brain from transient global ischemia/reperfusion by attenuating endoplasmic reticulum response-induced apoptosis through CHOP. PLoS ONE 2013, 8, e53431.

20. Aoki, M.; Tamatani, M.; Taniguchi, M.; Yamaguchi, A.; Bando, Y.; Kasai, K.; Miyoshi, Y.; Nakamura, Y.; Vitek, M.P.; Tohyama, M.; et al. Hypothermic treatment restores glucose regulated protein 78 (GRP78) expression in ischemic brain. Mol. Brain Res. 2001, 95, 117-128.

21. Xu, S.Y.; Hu, Y.F.; Li, W.P.; Wu, Y.M.; Ji, Z.; Wang, S.N.; Li, K.; Pan, S.Y. Intermittent Hypothermia Is Neuroprotective in an in vitro Model of Ischemic Stroke. Int. J. Biol. Sci. 2014, 10, 873-881.

22. Gess, B.; Hofbauer, K.H.; Wenger, R.H.; Lohaus, C.; Meyer, H.E.; Kurtz, A. The cellular oxygen tension regulates expression of the endoplasmic oxidoreductase ERO1-La. Eur. J. Biochem. 2003, 2235, 2228-2235, doi:10.1046/j.1432-1033.2003.03590.x.

23. May, D.; Itin, A.; Gal, O.; Kalinski, H.; Feinstein, E.; Keshet, E. Ero1-L alpha plays a key role in a HIF-1-mediated pathway to improve disulfide bond formation and VEGF secretion under hypoxia: Implication for cancer. Oncogene 2005, 24, 1011-1020, doi:10.1038/sj.onc. 1208325.

24. Raghubir, R.; Nakka, V.P.; Mehta, S.L. Endoplasmic reticulum stress in brain damage. Methods Enzymol. 2011, 489, 259-275.

(C) 2015 by the authors; licensee MDPI, Basel, Switzerland. This article is an open access article distributed under the terms and conditions of the Creative Commons Attribution license (http://creativecommons.org/licenses/by/4.0/). 